\title{
Imaging the Unimaginable: Desorption Electrospray Ionization - Imaging Mass Spectrometry (DESI-IMS) in Natural Product Research
}

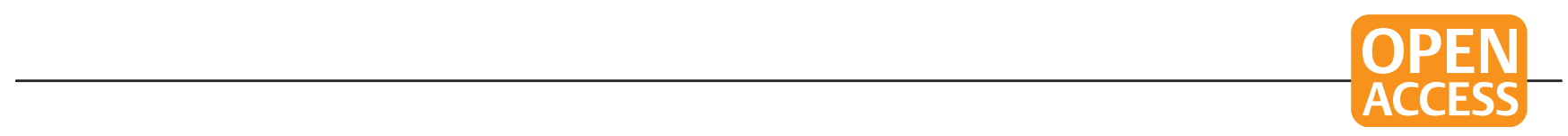

(ㄷ) (1) (옹

Authors

Delphine Parrot ${ }^{1}$, Stefano Papazian ${ }^{1}$, Daniel Foil ${ }^{1}$, Deniz Tasdemir ${ }^{1,2}$

\author{
Affiliations \\ 1 GEOMAR Centre for Marine Biotechnology, Research Unit \\ Marine Natural Products Chemistry, GEOMAR Helmholtz \\ Centre for Ocean Research Kiel, Germany \\ 2 Kiel University, Kiel, Germany
}

Key words

DESI-IMS, imaging mass spectrometry, chemical imaging, metabolomics, natural products

received November 6, 2017

revised December 15, 2017

accepted December 27, 2017

Bibliography

DOI https://doi.org/10.1055/s-0044-100188

Published online January 31, 2018 | Planta Med 2018; 84:

584-593 @ Georg Thieme Verlag KG Stuttgart · New York I ISSN 0032-0943

Correspondence

Prof. Dr. Deniz Tasdemir

GEOMAR Centre for Marine Biotechnology (GEOMAR-

Biotech), Research Unit Marine Natural Products Chemistry, GEOMAR Helmholtz Centre for Ocean Research Kiel

Am Kiel-Kanal 44, 24106 Kiel, Germany

Phone: + 494316004430 , Fax: + 494316004441

dtasdemir@geomar.de

\section{ABSTRACT}

Imaging mass spectrometry (IMS) has recently established itself in the field of "spatial metabolomics." Merging the sensitivity and fast screening of high-throughput mass spectrometry with spatial and temporal chemical information, IMS visualizes the production, location, and distribution of metabolites in intact biological models. Since metabolite profiling and morphological features are combined in single images, IMS offers an unmatched chemical detail on complex biological and microbiological systems. Thus, IMS-type "spatial metabolomics" emerges as a powerful and complementary approach to genomics, transcriptomics, and classical metabolomics studies. In this review, we summarize the current state-of-the-art IMS methods with a strong focus on desorption electrospray ionization (DESI)-IMS. DESI-IMS utilizes the original principle of electrospray ionization, but in this case solvent droplets are rastered and desorbed directly on the sample surface. The rapid and minimally destructive DESI-IMS chemical screening is achieved at ambient conditions and enables the accurate view of molecules in tissues at the $\mu \mathrm{m}$-scale resolution. DESI-IMS analysis does not require complex sample preparation and allows repeated measurements on samples from different biological sources, including microorganisms, plants, and animals. Thanks to its easy workflow and versatility, DESI-IMS has successfully been applied to many different research fields, such as clinical analysis, cancer research, environmental sciences, microbiology, chemical ecology, and drug discovery. Herein we discuss the present applications of DESI-IMS in natural product research.

\section{Introduction}

During the last 50 years, natural product research has benefited from the rapid advancement of MS (mass spectrometry) instrumentation, which enabled highly sensitive analysis of biological samples [1]. New MS ionization sources such as ESI [2] and MALDI [3] have revolutionized analytical chemistry, leading their inventors to receive the Nobel Prize in Chemistry in 2002. These "soft" ionization techniques enable the direct observation of natural compounds as intact ions and forever transformed MS from a niche tool of analytical chemistry to a ubiquitous technique uti- lized in life sciences research. Coupled to GC (gas chromatography) and LC (liquid chromatography), hyphenated MS instruments are now established worldwide as indispensable tools for high-throughput workflows. Being the most sensitive and the most powerful method, LC-MS nowadays represents the backbone of targeted and untargeted metabolomics approaches to detect and elucidate extremely low-abundance metabolites occurring in any type of biomass used in natural product research [4]. However, MS does not provide any information concerning the spatial and temporal distribution of metabolites in a biological sample. IMS complements traditional metabolomics and chemical 


$\begin{array}{ll}\text { ABBREVIATIONS } \\ \text { BOT } & \text { borderline ovarian tumors } \\ \text { CMC } & \text { carboxymethyl cellulose } \\ \text { DESI } & \text { desorption electrospray ionization } \\ \text { DMBA } & \text { 7,12-Dimethylbenz[a]anthracene } \\ \text { ESI } & \text { electrospray ionization } \\ \text { HCSC } & \text { high-grade serous carcinoma } \\ \text { IMS } & \text { imaging mass spectrometry } \\ \text { LAESI } & \text { laser ablation electrospray ionization } \\ \text { MALDI } & \text { matrix assisted laser desorption/ionization } \\ \text { m/z } & \text { mass-to-charge ratio } \\ \text { nano-DESI } & \text { nano desorption electrospray ionization } \\ \text { PTFE } & \text { polytetrafluoroethylen } \\ \text { SIMS } & \text { secondary ion mass spectrometry } \\ \text { VLCFA } & \text { very long chain fatty acid }\end{array}$

analyses by combining the qualitative and quantitative molecular information with spatiotemporal information, providing the capability to map specific molecules to $2 \mathrm{D}$ or $3 \mathrm{D}$ coordinates of the original sample [5].

IMS started developing more than two decades ago as the high-resolution frontier of material science and biology [3, 6, 7], and later gained large popularity in peptide and protein analyses, particularly in medicine and cancer diagnostics [8-11]. As of today, IMS has established itself as a highly efficient and reliable tool in capturing the image of both large and small molecules in various life science disciplines. IMS techniques combine the specificity, selectivity and sensitivity of MS with spatially resolved chemical information [3]. The ionization source or sampling probe is rastered across the sample surface to induce desorption of organic compounds into the gas phase, where they get ionized and differentiated through their $m / z$ [12]. This process is repeated sequentially over the whole sample until the mass spectra associated with every position on the sample are acquired. The ions of interest are then displayed in different colors and superimposed on the sample's picture, correlating with the natural distribution and the abundance of each $\mathrm{m} / \mathrm{z}$ ion throughout the sample. The higher the abundance of the molecular ion at a certain raster position, the greater the intensity of color that is displayed [13]. IMS does not require traditional sample extraction, which not only saves time and a tedious procedure but also eliminates problems (e.g., the production of artifacts). Moreover, depending on the type of IMS application, analysis of volatile and nonvolatile compounds may be achieved at the same time [14]. An IMS dataset contains a picture for each detected analyte [15]. IMS provides an untargeted in situ analysis of molecular species from complex samples to single cells, and from biological macromolecules to small metabolites, where metabolic signatures can be correlated with the histological and morphological features [16]. It provides scientists "molecular eyes" or "molecular microscopes" for analyzing the surface, tissue, and even cellular and subcellular metabolomes [5] as well as studying the dynamics and biological functions of metabolites of interests in a given organism. By providing a simplified analytical workflow and a chemical specificity at the morpho- logical level that was never possible before, IMS is now emerging as a revolutionary field at the interface between chemistry and (micro)biology. Not surprisingly, the IMS approach has been employed in over 100 microbiological studies since its first use in this field in the early 2000s [12]. Currently, it is being successfully applied to several areas including biomarker identification, tissue specific biosynthetic processes, microbe-microbe and host-microbe interactions, functional ecology, drug discovery, and chemical ecology.

Early IMS techniques, such as SIMS and MALDI, require the sample to be ionized at high vacuum. SIMS was first reported by Castaing and Soldzian in 1962 [17] and is the oldest IMS technique. Under high vacuum, a beam of high energy primary ions is focused onto the sample, physically perturbing the surface by a process known as "sputtering" [18], generating secondary ions, which are analyzed by the mass spectrometer [19]. One type of SIMS experiment called dynamic SIMS uses a continuous beam of primary ions to ablate the surface of the sample, allowing $3 \mathrm{D}$ as well as 2D imaging experiments [20,21]. The primary advantage of SIMS is spatial resolution, as the ion beam can be focused down to $50 \mathrm{~nm}$, enabling imaging on a subcellular level [22]. SIMS-IMS has been applied to the subcellular localization of biomarkers and metallo-drugs in cancer cells [23,24], as well as antibiotics in individual bacteria [25]. SIMS imaging has also been used to study nitrogen fixation in microbial communities [26] and marine invertebrates [27], as well as carbon flux in terrestrial worms [28]. As a result of the high-energy beam of ions, SIMS typically exhibits hard ionization, producing many fragments instead of molecular ions, potentially leading to the loss of information.

The well-established technique of MALDI-MS has a characteristically soft ionization, which produces a high ratio of molecularto-fragment ions. MALDI imaging was first reported by Caprioli et al. [8], who mapped certain peptides and proteins in various coated tissue sections or blotted imprint of the sections [8]. In a typical MALDI-IMS experiment, the sample is coated or co-crystalized with a light-absorbent matrix and irradiated with a pulse from a UV or IR laser. The matrix absorbs the radiation, transferring energy to the sample and aiding in ionization [29]. MALDI has several disadvantages, including high chemical noise in the low mass range $(<300 \mathrm{~m} / \mathrm{z})$ originating from the matrix components that may suppress crucial small molecule ions and the requirement for the sample to be mounted on a conductive surface. The laser desorption/ionization process also destroys the sample during MALDI-IMS. However, in comparison to several other IMS techniques discussed below, MALDI-IMS has superior spatial resolution (from $>5 \mu \mathrm{m}$ up to $>100 \mu \mathrm{m}$ ) [12]. Other advantages of MALDI-IMS include the wide mass range (from $300 \mathrm{~m} / \mathrm{z}$ up to $>5000 \mathrm{~m} / \mathrm{z}$ ) with which it can operate, good tolerance of variations in sample geometry, and a wide variety of established protocols for imaging, especially of microbial colonies [30]. With selection of a proper matrix, many types and sizes of compounds, ranging from proteins to lipids, peptides or secondary metabolites, can be visualized [12]. MALDI-IMS is the most established and most frequently used IMS technique in natural product research. Mainly led by the Dorrestein group at UC San Diego (USA), MALDI-IMS has been used in many excellent studies, for example, in identification of the biosynthetic origin of natural products 
from a bacterium-sponge symbiont [31], mechanisms of coral associated bacterium to protect its host from pathogenic fungi [32], and in examination of complex molecular interplays including suppression, enhanced production, biotransformation, and other metabolic exchanges in polymicrobial co-cultures [33]. MALDI imaging has been widely applied to natural product research, examining the spatial distribution of compounds in plants [34-39], bacteria $[40,41]$, cyanobacteria $[31,42]$, and various marine invertebrates [31,42-46].

In contrast to SIMS and MALDI, which operate under vacuum, recent IMS applications are embracing techniques that can be performed at ambient conditions with as little sample preparation as possible, such as LAESI-IMS and DESI-IMS. LAESI-IMS, invented by Nemes and Vertes and first described in 2007 [47], combines a mid-IR laser with an electrospray source. The sample is ablated by the laser, and the resulting cloud of particles is ionized as it passes through the electrospray plume [48]. The primary advantages of LAESI-IMS are that non-flat samples may be analyzed and that very little sample preparation is required [49]. Since the laser ablation removes a layer of the sample with each pulse, LAESI-IMS may be used for 3D as well as 2D sample analysis [50]. One key limitation of LAESI-IMS is that the sample needs to be rich in water in order to absorb energy sufficient for ablation from the laser pulse [47]. As LAESI-IMS physically removes layers of the sample during ablation, it is not suitable for analyses in which the sample needs to be analyzed repeatedly (e.g., for a time course study). Applications of LAESI in natural product research include the investigation of bacterial biofilms [51,52] and in the imaging of living plant tissues $[50,53,54]$. Combining LAESI-IMS analysis with bioassay has been shown to be a powerful tool for drug discovery [55].

Compared to other IMS techniques, DESI-IMS presents several advantages that render it well suited for natural products chemistry. Because SIMS-IMS and MALDI-IMS are both performed under vacuum, the samples must usually be freeze-dried before the analysis, making these techniques incompatible with living tissue. DESI differs from SIMS, MALDI, and LAESI in that it is considered a minimally destructive ionization method, allowing samples to be repeatedly analyzed in a time course experiment. The relatively limited sample preparation required for DESI-IMS analysis combined with minimally destructive sampling of living tissue enable DESI-IMS to fill a niche inaccessible by other IMS methodologies. These properties make DESI-IMS a potent tool for the investigation of microbe-microbe and host-microbe interactions. In this review, we focus on DESI-IMS technique, discussing the principles of the ionization mechanism, instrument optimization, sample preparation, and current applications in natural products chemistry, including terrestrial or marine microorganisms, plants, and animals, and finally its wide use in medical biochemistry and clinical research.

\section{DESI-IMS}

In 2004, DESI was introduced as a novel ESI technique by Cooks' group at Purdue University (USA) [56]. DESI relies on a soft ionization technique similar to ESI in LC-MS, which delivers mass spectra with very low fragmentation in either positive or negative ionization mode. The simple workflow and the ease with which a DESI source can be connected to existing mass spectrometers contribute to rising popularity of DESI in different fields of analytical chemistry. One of the main advantages in comparison to other IMS techniques is that DESI does not require extensive sample preparation such as matrix fixation in MALDI-IMS, resulting in a simplified analytical procedure for a rapid spatial and temporal identification of chemicals in intact biological samples, all under ambient conditions $[56,57]$. DESI-IMS can be applied to investigate highly complex sample surfaces, from polymeric materials to biological tissues and even fluids [58], allowing for the detection and semi-quantification of a variety of polar or non-polar small molecules [56, 59-61].

\section{Chemical and physical aspects of the ionization mechanism}

In DESI, high-velocity ionized solvent droplets desorb the analytes of interest directly from the sample surface, where compounds are solvated in a thin film. To achieve the chemical desorption, solvents are electro-sprayed under high voltage through an emitter capillary producing charged "primary" droplets, which are nebulized and then directed toward the sample. Metabolites located on the sample surface are in this way desorbed into gaseous "secondary" droplets delivering molecular ions entering the MS inlet where $\mathrm{m} / \mathrm{z}$ values are measured $[62,63]$ ( $\bullet$ Fig. 1). Depending on the polarity of the metabolite of interest, different spray solvents from the DESI source can be used for imaging. For the analysis of both polar and non-polar compounds, standard solvents such as $\mathrm{MeOH}$ or ACN are frequently used, usually with the addition of 2-5\% $\mathrm{H}_{2} \mathrm{O}$, but different solvent compositions have been employed according to the specific needs and application type [64, 65]. Overall, DESI-IMS has been shown to have a high degree of tolerance toward salt adducts formation and ionization suppression [66]. Interestingly, while the electrodynamics of droplets formation from the liquid ESI cone-jet have been thoroughly studied [67], the physical mechanism responsible for progeny droplet formation and impact at the sample surface during the DESI event is still elusive and not completely understood. Due to the high-pressure environment and the high kinetic energy of the molecules produced in DESI [58], the desorption process does not seem to depend on the physical particle sputtering mechanisms that govern gas ion collisions techniques such as SIMS $[18,58,68,69]$. Instead, several studies on ion-surface scattering processes in vacuum suggest that, during DESI, the molecules from surfaces may be ionized and released following a mechanisms known as "chemical sputtering" $[70,71]$. Fluid dynamics studies that simulated the electrochemical desorption mechanisms of DESI hypothesized that stochastic momentum-transfer events are the major forces leading to the formation of analyte-containing droplets $[63,72]$. These results also highlight the strong dependence on the contact angle and surface wettability of the materials as some of the major variables that govern the DESI process and that eventually affect the way metabolites are picked up from the surfaces and analyzed [72]. A modified version of DESI is nano-DESI, in which the microscale solvent extraction and desorption are achieved using two separate capillaries surrounding the sample in a "liquid bridge" $[73,74]$. Notably, nano-DESI is most suitable for direct sampling and IMS chemical profiling of small-scale wet 
surfaces that would suffer ablation from the strong nebulizing gas of DESI such as living microbial colonies in agar media and associated biofilms [74-76].

\section{DESI instrumental parameters and geometry}

Due to the sensitive intrinsic properties, optimization of different parameters prior to DESI analysis is routinely required in order to obtain the best desorption and ionization of metabolites in the sample and the highest reproducibility between experiments. The correct adjustment of these parameters will strongly influence the outcome of the analysis and the final imaging resolution. Among the most critical parameters are the electrospray solvent flow rate (e.g., $0.1-5 \mu \mathrm{L} / \mathrm{min}$ ) and voltage (1-8 kV), and the overall geometry of the DESI system, particularly the distance of sample surface to the DESI spray nozzle tip (d1) and to the MS-inlet $(d 2)$, as well as their respective incident and collection degree angles $(\alpha$ and $\beta)[58,77,78]$ ( $>$ Fig. 1). Common application guidelines of the instrument recommend utilizing a geometry configuration with larger tip-to-surface distances $(d 1=5-8 \mathrm{~mm})$, smaller incident angles $\left(\alpha=20-50^{\circ}\right)$, and higher voltages $(3-8 \mathrm{kV})$ for small molecules such as lipids or aromatic hydrocarbons, and opposite range of settings ( $\left.d 1=1-2 \mathrm{~mm} ; \alpha=60-90^{\circ}, 1-4 \mathrm{kV}\right)$ for larger molecules, such as proteins or nucleic acids [58]. Solvent flow rate and sprayer distance from the sample surface influence the quality of the analysis as they affect droplet sizes and their speed. At $2 \mu \mathrm{L} / \mathrm{min}$ solvent flow rate and $1130 \mathrm{kPa}$ nebulizing gas pressure, droplets have been measured to have an average diameter of 2-4 $\mu \mathrm{m}$ and an impact velocity of $120 \mathrm{~m} / \mathrm{s}$ [63]. High nebulizing flow rates are generally preferred as they produce smaller and faster droplets, which increase the desolvation efficiency. However, the upper limit is reached when droplets generated are too small and may evaporate before reaching the surface resulting in a lack of signal. Thus, given each geometry setup, the relationship between solvent and gas flow rates will strongly determine the final imaging resolution [77]. A typical spatial resolution can range between 50 and $200 \mu \mathrm{m}$, with an average resolution of 40-60 $\mu \mathrm{m}$ [79] and the highest resolution reported at $35 \mu \mathrm{m}$ during phospholipid analysis in mouse brain tissue in 2012 [79-81]. Increased resolution can be achieved by nano-DESI thanks to nano-spray ability to deliver droplets at lower velocity $(4 \mathrm{~m} / \mathrm{s})$, allowing a gentle deposition of charged reagents with minimal splashing and a spatial imaging to $<12 \mu \mathrm{m}[73,82]$.

\section{Sample preparation}

DESI-IMS has been successfully applied in several areas ranging from clinical medical research to pharmacology, and from natural product chemistry to chemical ecology. According to the application and the nature of the biological tissue, sample preparation may differ. DESI analysis is usually restricted to flat and preferably hard surfaces. Samples with smooth and regular surfaces can be usually analyzed directly with no sample preparation. In case of non-flat surfaces (for instance animal organs and tissues), cryosections can be prepared following commonly established IMS protocols [83]. In case of plants, preparation of DESI samples can be achieved in different ways. Flowers and leaves are often problematic as they present soft, irregular, and very absorbent surfaces, which may result in low or instable signal during imaging.

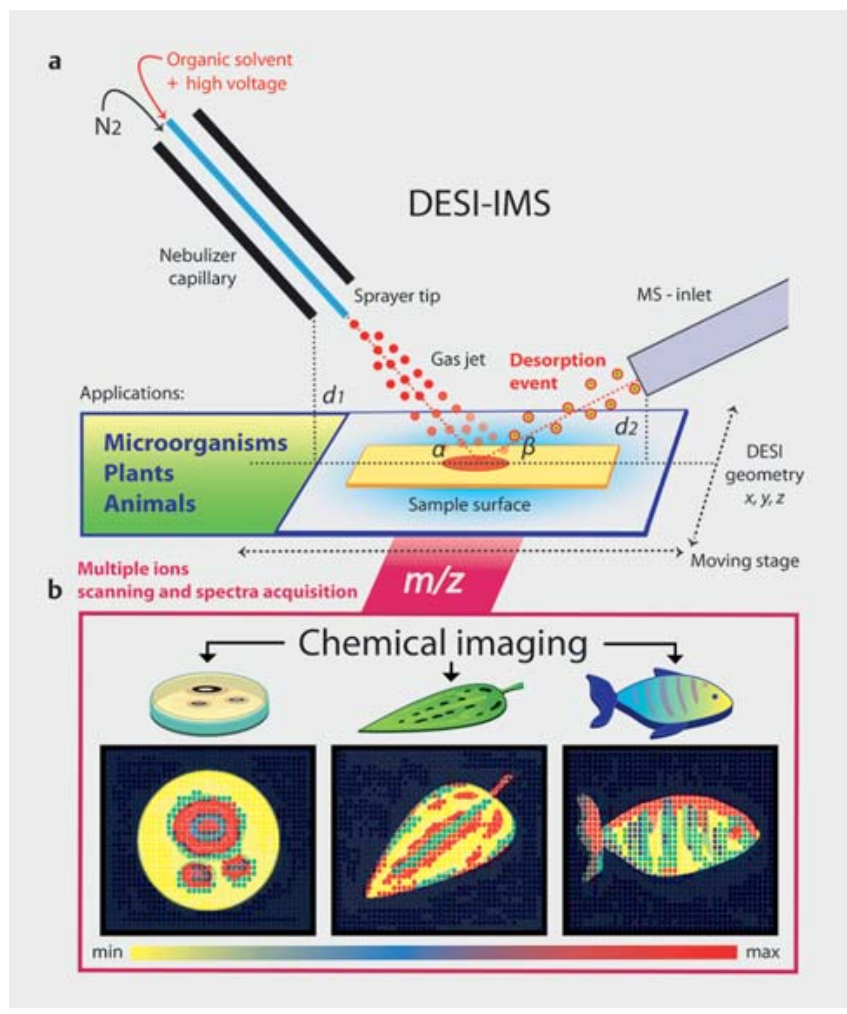

- Fig. 1 Graphic representation of the DESI-IMS workflow. a The ionization mechanism and desorption event are achieved directly at the sample surface to deliver molecular images (adapted from Takáts et al., 2004) [56]. b Relative intensities observed for multiple ions $(\mathrm{m} / \mathrm{z})$ represented with different colors in various biological systems (i.e., polymicrobial culture, plant and animal, respectively). Sensitive parameters, which strongly affect the resolution include the geometry between the DESI components ( $x, y, z$ axis), such as the distance of the sample surface to the sprayer tip (d1) and to the MS inlet ( $d 2)$.

In addition, most land plants contain wax cuticles on their leaf surface that are highly hydrophobic and can be difficult to penetrate by spraying solvents. As an alternative to direct analysis on plant surfaces, indirect sample analysis can be performed via "imprinting" of metabolites for instance on glass slides. However, ablation of metabolites deposited on the glass surface may occur rapidly, resulting in a loss of signal intensity over repeated measurements. Sorbent materials such as porous PTFE or TLC (thin-layer chromatography) silica plates appear more suitable for indirect tissue analysis by sample imprinting. Both PTFE and TLC plates have good absorbing properties that retain metabolites from the plants until desorption with DESI and have been applied for the imprinting of various plant organs and tissues [70-72,83]. TLC is a cheaper solution with similar performance to PTFE, but overall PTFE is currently reported as the best solution for DESI-IMS analysis of plant materials in terms of both reproducibility and quantitative ability [81, 85-87].

\section{Data analysis}

The datasets produced by DESI spatial mass scanning typically contain a large set of information and thus requires intensive 
post-acquisition analysis for data extraction, visualization, and interpretation. In this respect, developments in bioinformatics tools such as machine learning algorithms allows for advanced highthroughput data analysis [88]. For instance, deep learning and unsupervised neural network based methods have been successfully applied for the analysis of complex dataset from 3D-DESI-MS of tumor tissue, allowing for high dimensionality reduction and data clustering normally not achievable by classical linear methods [89]. Recently, a collaborative initiative sponsored by EMBL (European Molecular Biology Laboratory) in the framework of the European Research Program Horizon 2020 tackled the need for highthroughput analysis of high dimensionality data from MALDI and DESI-IMS and developed an open-source method that is available to test in its beta uploading using the MetaSpace cloud-server (http://metaspace2020.eu/). A similar project has been undertaken by the community of OpenMSI (https://openmsi.nersc.gov), which provides a high-performance web-based platform for the storage and management of IMS data, including tools for visualization and statistical analysis [90].

\section{Applications of DESI-IMS in Natural Product Research}

\section{Application of DESI-IMS on microorganisms}

Since 2008, DESI-IMS has been successfully applied for chemical profiling of metabolites located on surfaces and/or internal tissues, studying single or mixed microbial cultures and chemical interactions between them ( $\triangleright$ Table 1 ). However, the use of DESI-IMS on soft and irregular surfaces (such as agar media) is still a challenge today because the strong nebulizing gas of DESI can provoke an aperture in some cultures. Indeed, direct IMS of living colonies has mostly been accomplished by nano-DESI-IMS, more suitable method to imaging wet surface, on living communities such as Shewanella oneidensis, Bacillus subtilis, Streptomyces coelicolor, Mycobacterium smegmatis, and Pseudomonas aeruginosa for investigation of various chemical families (e.g., lipopeptides, rhamnolipids, quinolones, phenazines, glycopeptidolipids) [74]. However, analysis of $B$. subtilis by DESI-IMS or by nano-DESI-IMS has revealed, in both cases, the presence of surfactin-type lipopeptides.

One of the first applications of DESI-IMS directly on bacterial cultures aimed at identification of bacterial species based on their chemistry and particularly on the basis of their lipid constituents [91, 92]. For example, the cyclic lipopeptide surfactin C15, a wellknown metabolite produced by Bacillus sp., was observed on agar plates, permitting the taxonomical identification of $B$. subtilis directly on Petri dish [91]. DESI-IMS was also employed to analyze lipid composition on 16 bacterial samples to distinguish bacterial species and even subspecies using bacterial samples suspended in $70 \% \mathrm{EtOH}$. Chemotaxonomical identification of the bacterial species was based on the distribution of several major classes of lipids, including phosphotidylethanolamines, phosphotidylglycerols, and lysophospholipids, in positive and negative ionization modes. This lipidomic-type approach allowed the taxonomical characterization of several bacterial species including Staphylococcus au- reus, Escherichia coli, B. subtilis, and Salmonella sp. [92]. The lipidomic analysis of bacterial strains by DESI-IMS enabled the differentiation of Gram-positive and Gram-negative bacteria [92], providing new opportunities for microbiological research.

DESI-IMS has also been used for analyzing natural products (primary and secondary metabolites) directly from bacterial and/ or fungal cultures. For instance, metal scavenging siderophores were imaged directly from agar culture of Streptomyces wadayamensis [93], whereas several new polyhydroxyanthraquinones were identified as quorum sensing inhibitors in the guttate-forming Penicillium restrictum [94], an endophytic fungus isolated from the stems of a milk thistle, Silybum marianum (L.) Gaertn (Asteraceae). The DESI-IMS study showed that the polyhydroxyanthraquinones were produced by fungal mycelia and were expressed differentially over time. Also, the potent quorum sensing inhibitory polyhydroxyanthraquinones were observed to be concentrated at the fungal surface, whereas less potent compounds were diffused through the culture medium [94], illustrating the power of DESI-IMS to determine the spatiotemporal distribution as well as the specific production of natural products. Further investigation of bacterial central carbon metabolism performed by Jackson et al. [95] on E. coli allowed the detection of 13 out of 17 selected central carbon metabolites (i.e., metabolites involved in the integration of pathways of transport and oxidation of main carbon source inside the cell). Similarly, DESI-IMS was shown to be an effective method to understand chemical interactions/exchanges (e.g., antagonistic fungal interactions [96, 97], fungal/bacterial interactions [98], or metabolic exchange between bacterial species [99] directly). The interaction of micro- and macroorganisms with other organisms often relies on the production of secondary metabolites. Specific metabolite exchanges such as two lactones derivative (T39 butenolide and harzianolide), one hexaketide metabolite (sorbicillinol), and an unknown metabolite $\left(\mathrm{m} / \mathrm{z}[\mathrm{M}+\mathrm{H}]^{+}\right.$ 319.1) were revealed during the co-culturing of the commercially relevant phytopathogenic fungus Moniliophthora roreri (causing fungal cacao pest) and the fungal biocontrol agent Trichoderma harzianum [96]. Likewise, the production of phomopsinone A ( $\alpha$ pyrone derivatives) and T-2 toxin (mycotoxin) was shown during the co-culture of fungus Fusarium sp. and fungus Clohesyomyces aquaticus [97]. A proteobacterium, Burkholderia seminalis isolated from Saccharum officinarum L. (Poaceae) roots, was shown to inhibit the growth of multiple cacao pathogens by the production of rhamnolipids, and other unidentified metabolites [98]. DESI-IMS imaging of $B$. subtilis and $S$. coelicolor co-culture has highlighted the ability of $B$. subtilis to silence antibiotic production (in particular the production of benzo isochromane quinone polyketide actinorhodin) in S. coelicolor, giving B. subtilis a fitness advantage over S. coelicolor [99]. Such studies employing DESI-IMS do not only provide a better understanding for microbial interactions, but also offer new ecological perspectives-for example, the ability $T$. harzianum or $B$. seminalis to act as biocontrol agent against $M$. roreri and other cacao pathogens, respectively. Chemical imaging of microbial co-cultures has potential to be used as a tool for the discovery and the localization of new bioactive metabolites generated by the co-microorganisms. Those co-microorganisms modulate the activation or the suppression of specific metabolite production. 


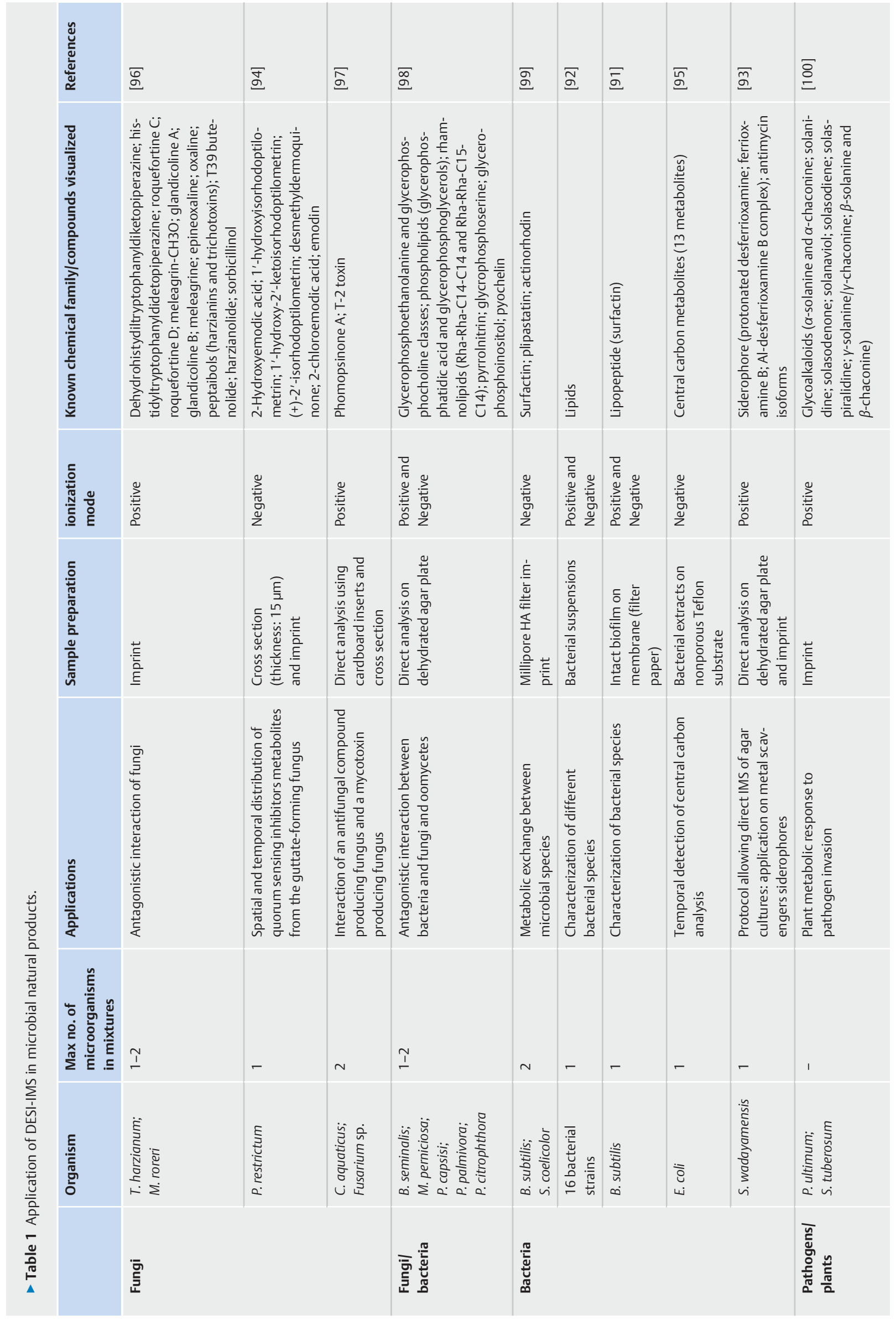




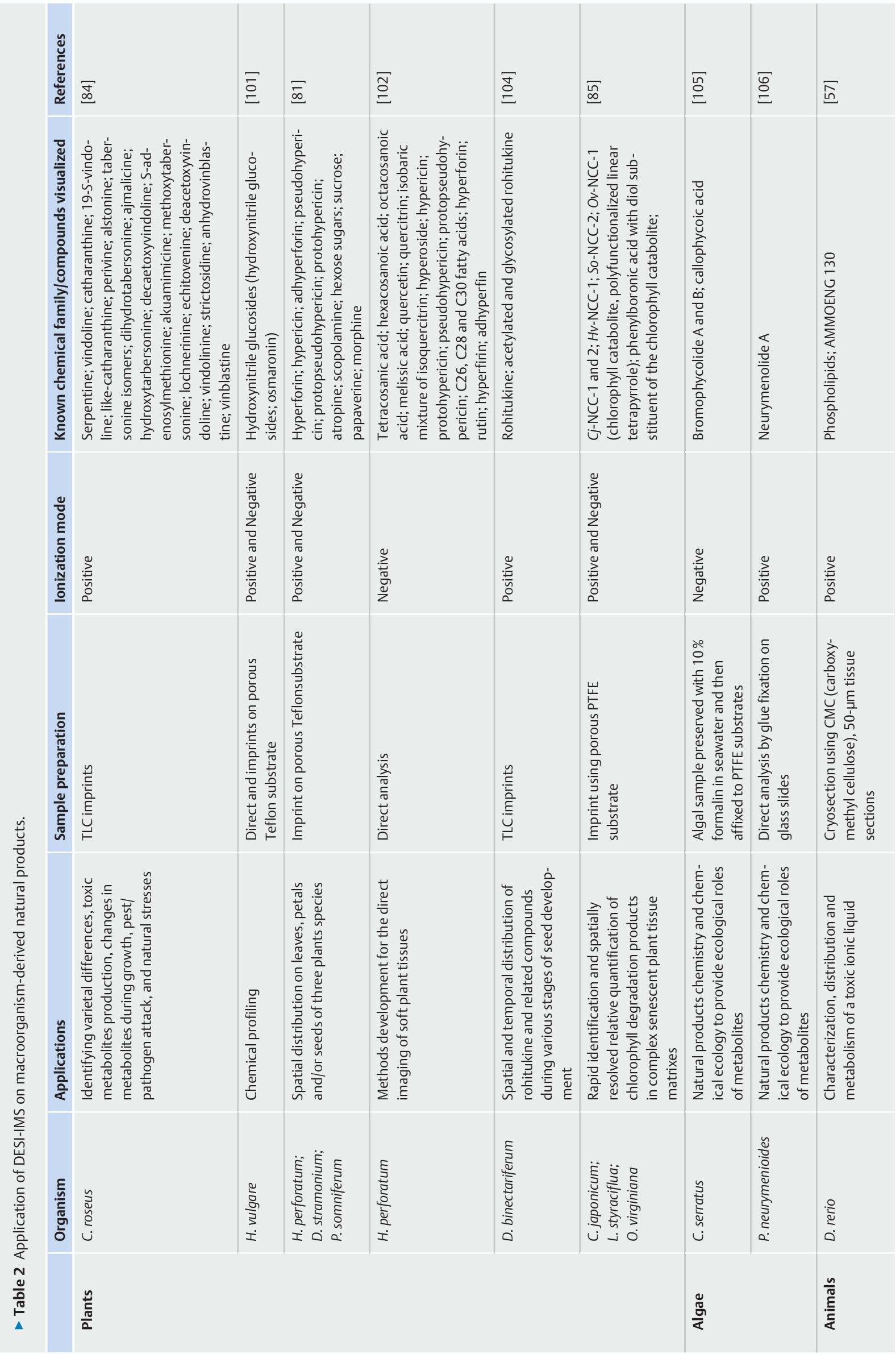




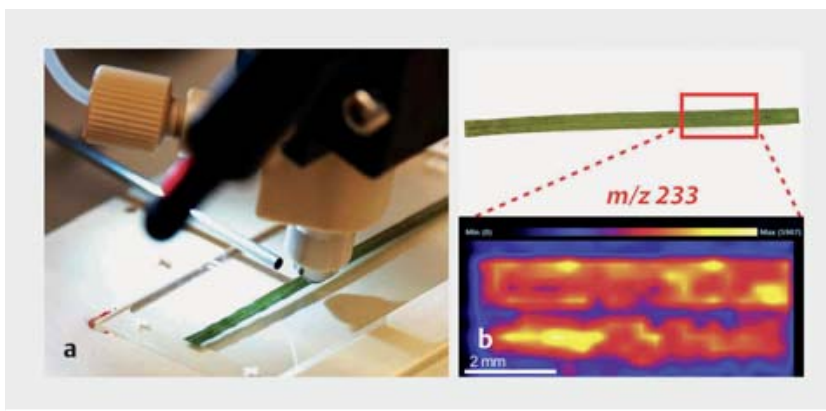

- Fig. 2 Application of DESI-IMS in our laboratory at GEOMAR for surface chemical imaging of marine plants from the Baltic Sea. a Direct surface analysis of a seagrass and (b) metabolite localization and relative abundance of $\mathrm{m} / \mathrm{z}$ ion $233[\mathrm{M}+\mathrm{H}]^{+}$, achieved using a rapid scanning on glass imprints at $200 \mu \mathrm{m}$ resolution (covered area approximately $12 \mathrm{~mm}^{2}$ ).

Plant-pathogen interactions have also been analyzed by DESI-IMS, linking plant responses to microbial pathogens as reported by Tata et al. [100]. Plants represent an important source of nutrients but very few studies on plant pathosystems (i.e., ecosystems defined by parasitism) are available. DESI-IMS was used to study the fluctuations of glycoalkaloids in sprouted potatolices infected by the fungal phytopathogen Pythium ultimum. After eight days of infection, it was observed that metabolic pathways were affected by the phytopathogen to increase or decrease the levels of in total 12 glycoalkaloids [100]. Therein, the DESI-IMS study permitted to determine the plant metabolic changes on the production of glycoalkaloid after infection by the fungal phytopathogen and demonstrated its useful application in plant pathosystems.

In summary, DESI-IMS has so far been used on microorganisms for (i) taxonomical identification of species, (ii) production and spatiotemporal distribution of (surface) metabolites, (iii) identifying metabolic exchanges between bacterial species, (iv) antagonistic fungal/fungal and fungal/bacterial interactions, and (v) elucidation of metabolic responses of plants to pathogenic infections $(\triangleright$ Table 1$)$. These studies open up new perspectives in (micro)biology, and in the understanding of biological systems from a chemical angle.

\section{Application of DESI-IMS on macroorganisms}

Several examples of DESI-IMS analyses have been reported on macroorganisms, including analyses on plants, algae, and fish ( $\triangleright$ Table 2).

With regard to plants, DESI-IMS has principally been applied on the imprints of leaves $[81,84,85,101,102]$, flowers and petals $[84,101,102]$, fruits [103], and seeds [104] ( Table 2). The cuticle of plants is dominated by metabolites such as fatty acids with aliphatic tails longer than 22 carbons. These VLCFAs represent a physical morphological barrier in leaves and petals, presenting an obstacle for DESI-IMS analysis. To overcome this difficulty, a ternary solvent system, $\mathrm{CHCl}_{3}-\mathrm{ACN}-\mathrm{H}_{2} \mathrm{O}(1: 1: 0.04)$, was developed and used to analyze the cuticle itself as well as the subcuticular metabolites directly by DESI-IMS [102]. The leaves and petals of Hypericum perforatum L. (Clusiaceae) were analyzed in several studies [64, 70, 81, 82, 85], in which the detection and localization of several metabolites were reported. The phloroglucinol derivative hyperforin was shown to be localized in the translucent glands, while hypericin (an anthraquinone derivative) was present in the dark glands. A number of other phloroglucinol, flavonoid, and anthraquinone derivatives known from Hypericum sp. (adhyperforin, pseudohypericin, protopseudohypericin, protohypericin, rutin, quercetin, phloroglucinol), as well as VLCFAs, were detected by indirect analysis (imprints) [81] or direct analysis using a ternary solvent system and/or after surface extraction by $\mathrm{CHCl}_{3}$ [102]. Similarly, the distribution of leaf metabolites of Datura stramonium L. (Solanaceae) was analyzed, revealing the presence of the major tropane alkaloids atropine and scopolamine. Both compounds were located principally in the leaf ribs and veins, suggesting their transport within the plant [81].

Similar approaches were also performed on other plants, such as Papaver somniferum L. (Papaveraceae) [81], Catharanthus roseus (L.) G.Don (Apocynaceae) [84], Hordeum vulgare L. (Poaceae) [101], Cercidiphyllum japonicum Siebold \& Zucc (Cercidiphyllaceae), Liquidambar styraciflua L. (Hamamelidaceae), Ostrya virginiana K.Koch (Corylaceae) [85], Lotus japonicus (Regel) K.Larsen (Leguminosae), Manihot esculenta Crantz (Euphorbiaceae) [87], Ginkgo biloba L. (Ginkgoaceae) [104], and strawberry (Fragaria $x$ ananassa Duch. [Rosaceae]) [103], indicating the capability of DESI-IMS to map various classes of metabolites (e.g., terpenoid indole alkaloids, hydroxynitrile glucosides) on various plant organs ( $\triangleright$ Table 2). The spatial and temporal distribution of rohitukine, a chromone alkaloid with anti-inflammatory, anticancer, and immunomodulatory activities, was imaged during the seed development of Dysoxylum binectariferum Hook.f. (Meliaceae). Rohikutine accumulation was shown to be more important during seed development and its increase was specifically located in the embryo, cotyledons, and to a lesser extent in the seed coat [104]. DESI-IMS studies on leaves, flowers, or seeds were performed to determine metabolite distribution at a specific time or during various plant developmental stages.

DESI-IMS has also been used to study molecular distribution of bioactive natural products in marine organisms, such as seaweeds ( $\vee$ Table 2). The DESI-IMS analysis of the tropical red seaweed Callophycus serratus revealed the presence of the macrocyclic halogenated-benzoates, bromophycolide A and B on the surface of the alga [105]. Both compounds inhibit the growth of Lindra thalassiae, a marine fungus that infects diverse hosts ranging from brown algae to seagrasses. The natural concentrations of these two metabolites were shown to be more than sufficient to display an antifungal activity in the algal surface patches, suggesting the importance of secondary metabolites for chemically mediated biological processes [105]. The compounds were observed also within internal algal tissue by DESI-IMS. The fact that bromophycolides are not homogenously distributed on the algal surface but associated with distinct patches could be due to the presence of tissue damage, indicating the chemical defense of $C$. serratus to fungal infection. Seaweeds and corals often occur in close proximity in the same environment. As coral reefs are declining globally, seaweeds are commonly replacing corals. However, the mechanism of the increasing coral-algal interactions is poorly understood. Andras et al. [106] employed DESI-IMS to visualize 

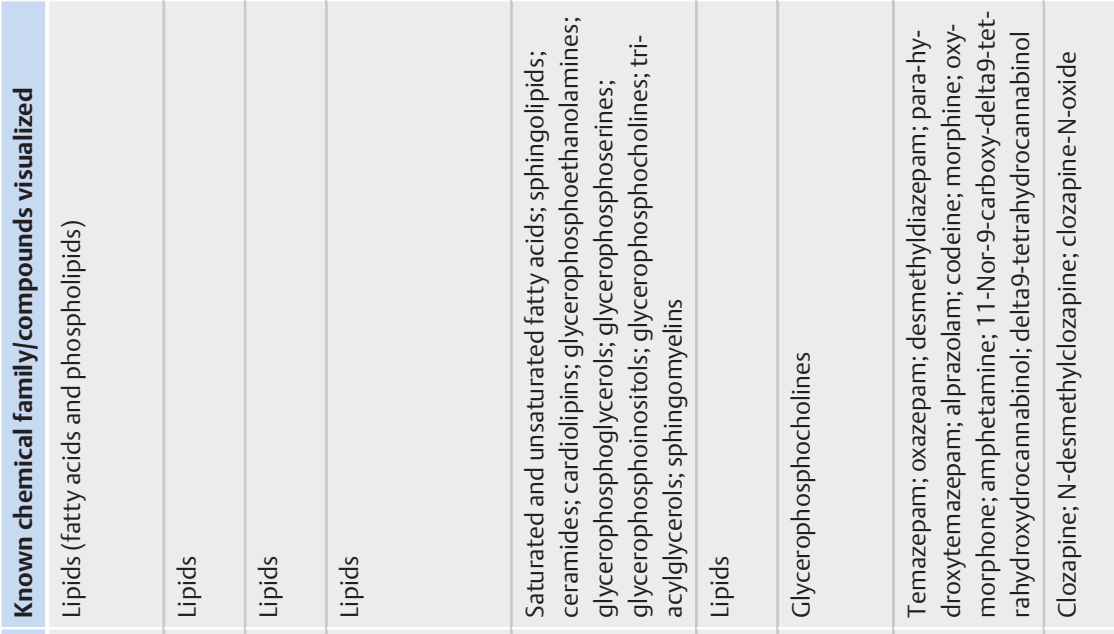

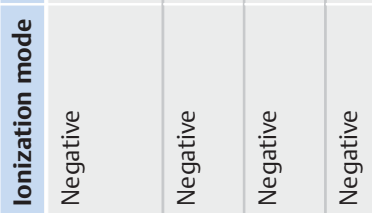

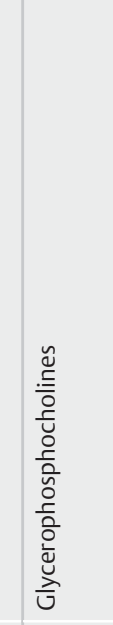

\section{量}

In

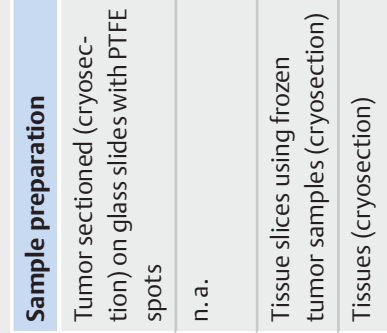

言

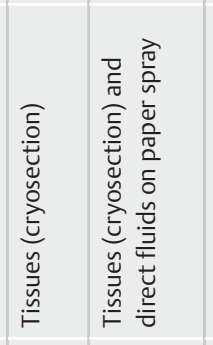

产

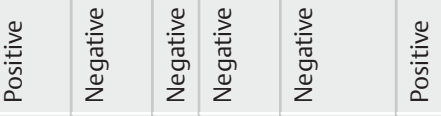
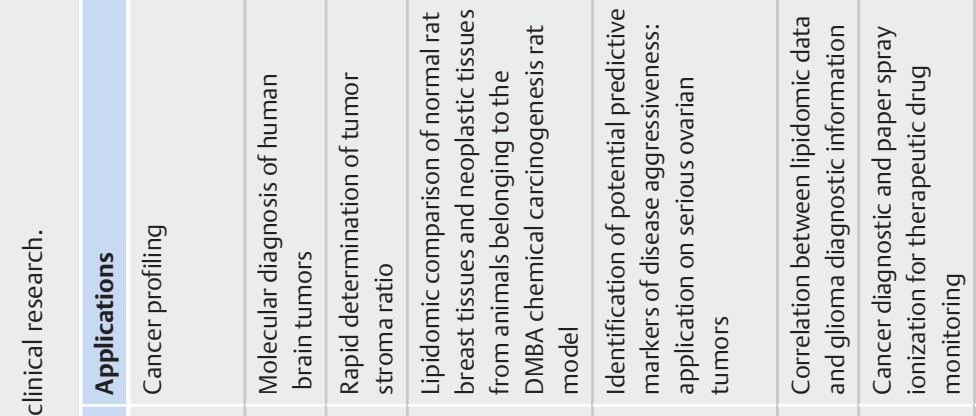

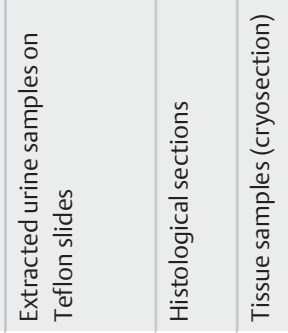

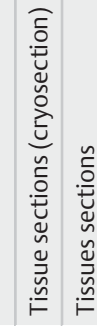

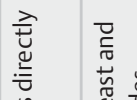

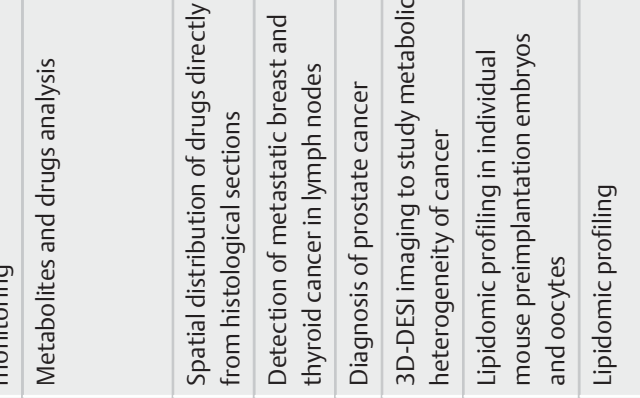

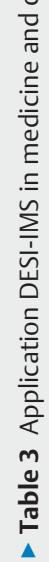

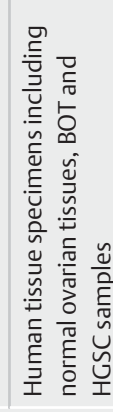

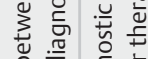

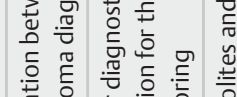

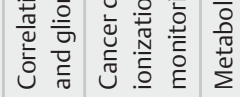

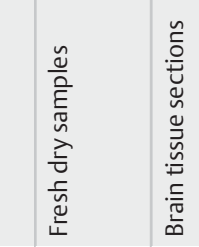

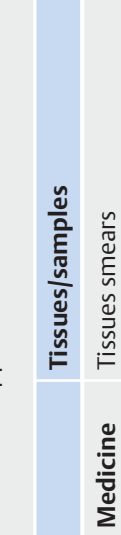
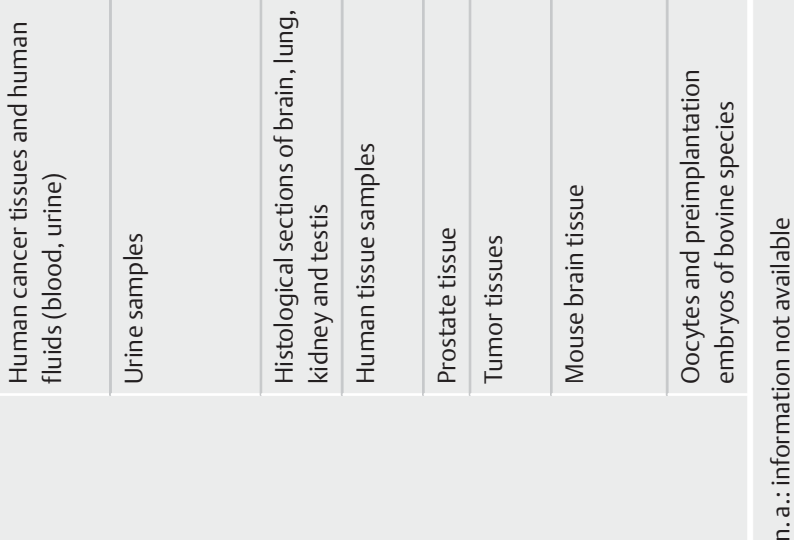
and quantify neurymenolide A, an unusual cyclophane derivative isolated from the red alga Phacelocarpus neurymenioides. Neurymenolide $A$ is an allelopathic agent occurring on the surface of the live alga that damages the coral Porites rus by direct contact with the alga. This study elegantly shows the potential of DESI-IMS in chemical ecology studies. In our laboratory, we have been applying DESI-IMS to Baltic Sea plants and seaweeds to determine their surface metabolome, in combination with classical metabolomics approaches ( $\triangleright$ Fig. 2 ).

There is only one study that has reported the use of DESI-IMS on the whole body zebrafish (Danio rerio) by cryosectioning [43]. This study aimed at localizing the accumulation of a mildly toxic ionic liquid AMMOENG 130 in zebrafish tissues, after exposure of the zebrafish to varying concentrations of this liquid. The ionic liquids are found in large quantities in detergents and softeners, and are potentially toxic. In particular, AMMOENG 130 was found to be very toxic against $D$. rerio (i.e., more toxic than 13 out of 15 common ionic liquids). DESI-IMS experiment on $D$. rerio revealed the accumulation of this toxin in the respiratory and nervous system of the fish, suggesting that it is potentially a neurotoxin. Consequently, DESI-IMS analysis of macroorganisms opens new avenues in other research fields such as ecotoxicology for biomonitoring of toxic compounds.

\section{Application of DESI-IMS in medicine and clinical research}

Similar to MALDI-IMS, the dominant application area of DESI-IMS is medical research, where it enables a rapid and accurate method to visualize biomarkers in biological tissues. In particular, DESI-IMS has been demonstrated to be very efficient in lipid composition analysis. Lipids play key roles in various cytological processes and in cell signaling; hence, the analysis of lipid composition in biological tissues is crucial to support morphological investigations, diagnosis, and characterization of pathophysiological processes such as neurodegenerative and cardiovascular diseases, as well as neoplastic processes. Tissue profiling of lymphoma, gliomas, gastric, liver, prostate, and breast cancer have all showed how drastic change in lipid composition can be used as biomarkers. DESI-IMS has been applied in medical research as reported by at least five publications in 2017 and more than 14 publications since 2007 ( $\triangleright$ Table 3). Selected examples are described below to illustrate medical aspects of DESI-IMS applications.

Eberlin et al. [107] used lipidomic data as biomarkers to rapidly classify 36 human gliomas including oligodendroglioma, astrocytoma, and oligostrocytoma at different histologic grades and varied tumor cell concentrations. The combination of DESI-IMS, multivariate analysis, and machine learning was applied to recognize glioma subtypes and grade on the basis of the World Health Organization tumor classification system. The analysis resulted in a recognition capability of greater than $99 \%$ and a cross-validation of more than $97 \%$ based on 128 peaks for the subtype, 123 peaks for the grade, and 136 peaks for the concentration. Furthermore, small molecule analysis (Krebs cycle intermediates metabolites and carbohydrates) combined with lipid composition was used to distinguish prostate cancer from normal tissues and to improve the accuracy of prostate cancer identification [108]. These models permitted the differentiation of prostate cancer from benign specimens with nearly $90 \%$ accuracy per patient. Glucose/citrate ratio, in parallel to lipids composition, could also be used to accurately monitor the occurrence of prostate cancer [108]. In the majority of cancer diagnoses by DESI-IMS, lipid composition was of key importance to distinguish tumor tissues from normal tissues ( $\triangleright$ Table 3) [108]. DESI-IMS was used to record the spatial intensity distribution of a drug, clozapine, directly from histological sections of brain, lung, kidney, and testis [60], in addition to cancer diagnosis applications. In another study, Miyamoto et al. [109] combined microscopy, MALDI-IMS and nano-DESI to reveal changes in glucose metabolism and the accumulation of sphingomyelin metabolites in the glomeruli of the diabetic mice fed with high-fat diet. This shows the great potential of the technique in various areas of medical research, including metabolic disorders.

On the whole, DESI-IMS has been successfully applied in various research fields including microbiology, ecotoxicology, ecology, forensics, embryology, chemistry, and medicine, presenting a fast, easy, and reliable direct/indirect analysis of biological samples. DESI-IMS has found applications in other research fields-for instance, in astrophysics to detect and identify the spatial distribution of organic compounds on meteorites' surface [110] indicating its potential in so many other disciplines.

\section{Conclusions and Future Perspectives}

IMS techniques have already opened new avenues in several areas of life sciences, including medicine, microbiology, and natural product chemistry. The IMS surpasses all existing molecular analysis methods (i.e., genomics, transcriptomics and metabolomics) by giving crucial and simultaneous spatial information on molecules. Therefore, various IMS techniques with different ionization modes and workflows are being adopted by scientists to address questions presented by spatial metabolomics on various biological systems. However, all IMS techniques have drawbacks and limitations in instrumentation, sample preparation, metabolites annotation, resolution, and data analysis. Considering their ever-increasing popularity, it is foreseeable that the IMS techniques will rapidly improve to move forward and find even more applications in life and medical sciences, and potentially in industry. Specifically, IMS techniques will bring metabolomics research to a paradigm shift and completely change the way how we interrogate biological systems and provide new approaches in drug discovery and medicine. With future developments, IMS has the power to transform our ability to interrogate natural processes for example, better understanding host-microbe and microbe-microbe interaction, biosynthesis of natural products, chemical ecology, virulence factors, and disease states. Continuous improvement will be crucial for the advancement of IMS and its contribution in our understanding of life and metabolic processes.

\section{Acknowledgements}

SP acknowledges the Foundation Blanceflor Boncompagni Ludovisi scholarship. DF is supported by the MarPipe project (improving the flow in the pipeline of the next generation of marine biodiscovery scientists) funded through the European Commission H2020-MSCA-ITN-ETN scheme, GA721421. 


\section{Conflict of Interest}

The authors declare that they have no conflicts of interest.

\section{References}

[1] Jarmusch AK, Cooks RG. Emerging capabilities of mass spectrometry for natural products. Nat Prod Rep 2014; 31: 730-738

[2] Fenn J, Mann M, Meng C, Wong S, Whitehouse C. Electrospray ionization for mass spectrometry of large biomolecules. Science 1989; 246: 64-71

[3] Tanaka K, Waki H, Ido Y, Akita S, Yoshida Y, Yoshida T, Matsuo T. Protein and polymer analyses up to $\mathrm{m} / \mathrm{z} 100000$ by laser ionization time-offlight mass spectrometry. Rapid Commun Mass Spectrom 1988; 2 : $151-153$

[4] Aksenov AA, da Silva R, Knight R, Lopes NP, Dorrestein PC. Global chemical analysis of biology by mass spectrometry. Nat Rev Chem 2017; 1: 120

[5] Petras D, Jarmusch AK, Dorrestein PC. From single cells to our planet-recent advances in using mass spectrometry for spatially resolved metabolomics. Curr Opin Chem Biol 2017; 36: 24-31

[6] Chabala JM, Soni KK, Li J, Gavrilov KL, Levi-Setti R. High-resolution chemical imaging with scanning ion probe SIMS. Int ] Mass Spectrom Ion Process 1995; 143: 191-212

[7] Chaurand P, Schwartz SA, Billheimer D, Xu B], Crecelius A, Caprioli RM. Integrating histology and imaging mass spectrometry. Anal Chem 2004; 76: 1145-1155

[8] Caprioli RM, Farmer TB, Gile J. Molecular imaging of biological samples: localization of peptides and proteins using MALDI-TOF MS. Anal Chem 1997; 69: 4751-4760

[9] Stoeckli M, Chaurand P, Hallahan DE, Caprioli RM. Imaging mass spectrometry: a new technology for the analysis of protein expression in mammalian tissues. Nat Med 2001; 7: 493-496

[10] Masumori N, Thomas TZ, Chaurand P, Case T, Paul M, Kasper S, Caprioli RM, Tsukamoto T, Shappell SB, Matusik RJ. A probasin-large T antigen transgenic mouse line develops prostate adenocarcinoma and neuroendocrine carcinoma with metastatic potential. Cancer Res 2001; 61: 2239-2249

[11] Caldwell RL, Caprioli RM. Tissue profiling by mass spectrometry. Mol Cell Proteomics 2005; 4: 394-401

[12] Dunham SJB, Ellis JF, Li B, Sweedler JV. Mass spectrometry imaging of complex microbial communities. Acc Chem Res 2016; 50: 96-104

[13] Esquenazi E, Dorrestein PC, Gerwick WH. Probing marine natural product defenses with DESI-imaging mass spectrometry. Proc Natl Acad Sci 2009; 106: 7269-7270

[14] Li LP, Feng BS, Yang JW, Chang CL, Bai Y, Liu HW. Applications of ambient mass spectrometry in high-throughput screening. Analyst 2013; 138: 3097-3103

[15] McDonnell AL, Heeren RM. Imaging mass spectrometry. Mass Spectrom Rev 2007; 26: 606-643

[16] Ho YN, Shu L], Yang YL. Imaging mass spectrometry for metabolites: technical progress, multimodal imaging, and biological interactions. Wiley Interdiscip Rev Syst Biol Med 2017; 9: 1-32

[17] Castaing R, Slodzian G. Microanalyse par émission secondaire. J Microsc (Paris) 1962; 1: 395-410

[18] Smentkowski VS. Trends in sputtering. Prog Surf Sci 2000; 64: 1-58

[19] Liebl H. Ion microprobe mass analyzer. ] Appl Phys 1967; 38: 5277-5283

[20] Boxer SG, Kraft ML, Weber PK. Advances in imaging secondary ion mass spectrometry for biological samples. Annu Rev Biophys 2009; 38: 53-74

[21] Fletcher JS, Vickerman JC. Secondary ion mass spectrometry: characterizing complex samples in two and three dimensions. Anal Chem 2013; 85: 610-639
[22] Chandra S, Smith DR, Morrison GH. Peer reviewed: a subcellular imaging by dynamic SIMS ion microscopy. Anal Chem 2000; 72: 104A-114A

[23] Wu K, Jia F, Zheng W, Luo Q, Zhao Y, Wang F. Visualization of metallodrugs in single cells by secondary ion mass spectrometry imaging. JBIC J Biol Inorg Chem 2017; 22: 653-661

[24] Chandra S, Tjarks W, Lorey DR, Barth RF. Quantitative subcellular imaging of boron compounds in individual mitotic and interphase human glioblastoma cells with imaging secondary ion mass spectrometry (SIMS). J Microsc 2008; 229: 92-103

[25] Tian H, Six DA, Krucker T, Leeds JA, Winograd N. Subcellular chemical imaging of antibiotics in single bacteria using $\mathrm{C} 60$-secondary ion mass spectrometry. Anal Chem 2017; 89: 5050-5057

[26] Dekas AE, Poretsky RS, Orphan V]. Deep-sea Archaea fix and share nitrogen in methane-consuming microbial consortia. Science 2009; 326: 422-426

[27] Lechene CP, Luyten Y, McMahon G, Distel DL. Quantitative imaging of nitrogen fixation by individual bacteria within animal cells. Science 2007; 317: 1563-1566

[28] Vidal A, Remusat L, Watteau F, Derenne S, Quenea K. Incorporation of 13C labelled shoot residues in Lumbricus terrestris casts: a combination of transmission electron microscopy and nanoscale secondary ion mass spectrometry. Soil Biol Biochem 2016; 93: 8-16

[29] Karas M, Bachmann D, Bahr U, Hillenkamp F. Matrix-assisted ultraviolet laser desorption of non-volatile compounds. Int J Mass Spectrom Ion Process 1987; 78: 53-68

[30] Watrous JD, Dorrestein PC. Imaging mass spectrometry in microbiology. Nat Rev Microbiol 2011; 9: 683-694

[31] Simmons TL, Coates RC, Clark BR, Engene N, Gonzalez D, Esquenazi E, Dorrestein PC, Gerwick WH. Biosynthetic origin of natural products isolated from marine microorganism-invertebrate assemblages. Proc Natl Acad Sci U S A 2008; 105: 4587-4594

[32] Moree W], Yang JY, Zhao X, Liu WT, Aparicio M, Atencio L, Ballesteros J, Sanchez J, Gavilan RG, Gutiarrez M, Dorrestein PC. Imaging mass spectrometry of a coral microbe interaction with fungi. J Chem Ecol 2013; 39: 1045-1054

[33] Moree W], Phelan VV, Wu CH, Bandeira N, Cornett DS, Duggan BM, Dorrestein PC. Interkingdom metabolic transformations captured by microbial imaging mass spectrometry. Proc Natl Acad Sci 2012; 109: $13811-13816$

[34] Li B, Bhandari DR, Römpp A, Spengler B. High-resolution MALDI mass spectrometry imaging of gallotannins and monoterpene glucosides in the root of Paeonia lactiflora. Sci Rep 2016; 6: 36074

[35] Shiono K, Hashizaki R, Nakanishi T, Sakai T, Yamamoto T, Ogata K, Harada K, Ohtani H, Katano H, Taira S. Multi-imaging of cytokinin and abscisic acid on the roots of rice (Oryza sativa) using matrix-assisted laser desorption/ionization mass spectrometry. J Agric Food Chem 2017; 65: 7624-7628

[36] Wu W, Liang Z, Zhao Z, Cai Z. Direct analysis of alkaloid profiling in plant tissue by using matrix-assisted laser desorption/ionization mass spectrometry. J Mass Spectrom 2007; 42: 58-69

[37] Shroff R, Vergara F, Muck A, Svatos A, Gershenzon J. Nonuniform distribution of glucosinolates in Arabidopsis thaliana leaves has important consequences for plant defense. Proc Natl Acad Sci 2008; 105: 61966201

[38] Anderson DMG, Carolan VA, Crosland S, Sharples KR, Clench MR. Examination of the distribution of nicosulfuron in sunflower plants by matrixassisted laser desorption/ionisation mass spectrometry imaging. Rapid Commun Mass Spectrom 2009; 23: 1321-1327

[39] Li B, Bhandari DR, Janfelt C, Römpp A, Spengler B. Natural products in Glycyrrhiza glabra (licorice) rhizome imaged at the cellular level by atmospheric pressure matrixassisted laser desorption/ionization tandem mass spectrometry imaging. Plant J 2014; 80: 161-171 
[40] Gonzalez DJ, Haste NM, Hollands A, Fleming TC, Hamby M, Pogliano K, Nizet V, Dorrestein PC. Microbial competition between Bacillus subtilis and Staphylococcus aureus monitored by imaging mass spectrometry. Microbiology 2011; 157: 2485-2492

[41] Yang YL, Xu Y, Straight P, Dorrestein PC. Translating metabolic exchange with imaging mass spectrometry. Nat Chem Biol 2009; 5: 885-887

[42] Esquenazi E, Coates C, Simmons L, Gonzalez D, Gerwick WH, Dorrestein PC. Visualizing the spatial distribution of secondary metabolites produced by marine cyanobacteria and sponges via MALDI-TOF imaging. Mol Biosyst 2008; 4: 562-570

[43] Genji T, Fukuzawa S, Tachibana K. Distribution and possible function of the marine alkaloid, norzoanthamine, in the zoanthid Zoanthus sp. using MALDI imaging mass spectrometry. Mar Biotechnol 2010; 12: 81-87

[44] Elnaggar MS, Ebada SS, Ashour ML, Ebrahim W, Singab A, Lin W, Liu Z, Proksch P. Two new triterpenoids and a new naphthoquinone derivative isolated from a hard coral-derived fungus Scopulariopsis sp. Fitoterapia 2017; 116: 126-130

[45] Waters AL, Peraud O, Kasanah N, Sims JW, Kothalawala N, Anderson MA, Abbas SH, Rao KV, Jupally VR, Kelly M, Dass A, Hill RT, Hamann MT. An analysis of the sponge Acanthostrongylophora igens' microbiome yields an actinomycete that produces the natural product manzamine A. Front Mar Sci 2014; 1: 1789-1802

[46] Yarnold JE, Hamilton BR, Welsh DT, Pool GF, Venter DJ, Carroll AR. High resolution spatial mapping of brominated pyrrole-2-aminoimidazole alkaloids distributions in the marine sponge Stylissa flabellata via MALDImass spectrometry imaging. Mol Biosyst 2012; 8: 2249-2259

[47] Nemes P, Vertes A. Laser ablation electrospray ionization for atmospheric pressure, in vivo, and imaging mass spectrometry. Anal Chem 2007; 79: 8098-8106

[48] Nemes P, Vertes A. Laser Ablation Electrospray Ionization Mass Spectrometry: Mechanisms, Configurations and imaging Applications. In: Domin M, Cody R, eds. Ambient Ionization Mass Spectrometry. London: Royal Society of Chemistry; 2014: 348-371

[49] Bartels B, Kulkarni P, Danz N, Bocker S, Saluz HP, Svatos A. Mapping metabolites from rough terrain: laser ablation electrospray ionization on non-flat samples. RSC Adv 2017; 7: 9045-9050

[50] Nemes P, Barton AA, Li Y, Vertes A. Ambient molecular imaging and depth profiling of live tissue by infrared laser ablation electrospray ionization mass spectrometry. Anal Chem 2008; 80: 4575-4582

[51] Dean SN, Walsh C, Goodman H, Van Hoek ML. Analysis of mixed biofilm (Staphylococcus aureus and Pseudomonas aeruginosa) by laser ablation electrospray ionization mass spectrometry. Biofouling 2015; 31: 151161

[52] Nemes P, Vertes A. Atmospheric-pressure molecular imaging of biological tissues and biofilms by LAESI mass spectrometry. J Vis Exp 2010; 43: pii:2097. doi:10.3791/2097

[53] Bartels B, Svatoš A. Spatially resolved in vivo plant metabolomics by laser ablation-based mass spectrometry imaging (MSI) techniques: LDI-MSI and LAESI. Front Plant Sci 2015; 6: 1-7

[54] Etalo D, de Vos RC, Joosten MH, Hall R. Spatially-resolved plant metabolomics: some potentials and limitations of laser-ablation electrospray ionization (LAESI) mass spectrometry metabolite imaging. Plant Physiol 2015; 169: 1424-1435

[55] Motley JL, Stamps BW, Mitchell CA, Thompson AT, Cross ], You ], Powell DR, Stevenson BS, Cichewicz RH. Opportunistic sampling of roadkill as an entry point to accessing natural products assembled by bacteria associated with non-anthropoidal mammalian microbiomes. I Nat Prod 2017; 80: 598-608

[56] Takáts Z. Mass spectrometry sampling under ambient conditions with desorption electrospray ionization. Science 2004; 306: 471-472

[57] Perez C], Tata A, de Campos ML, Peng C, Ifa DR. Monitoring toxic ionic liquids in zebrafish (Danio rerio) with desorption electrospray ionization mass spectrometry imaging (DESI-MSI). I Am Soc Mass Spectr 2017; 28: $1136-1148$

[58] Takáts Z, Wiseman JM, Cooks RG. Ambient mass spectrometry using desorption electrospray ionization (DESI): instrumentation, mechanisms and applications in forensics, chemistry, and biology. J Mass Spectrom 2005; 40: 1261-1275

[59] Eberlin LS, Ferreira CR, Dill AL, Ifa DR, Cooks GR. Desorption electrospray ionization mass spectrometry for lipid characterization and biological tissue imaging. Biochim Biophys Acta 2011; 1811: 946-960

[60] Wiseman JM, Ifa DR, Zhu Y, Kissinger CB, Manicke NE, Kissinger PT, Cooks RG, Wiseman JM, Ifa DR, Zhu Y, Kissinger CB, Manicke NE, Kissinger PT, Cooks RG. Desorption electrospray ionization mass spectrometry: imaging drugs and metabolites in tissues. Proc Natl Acad Sci US A 2008; 105: 18120-18125

[61] Manicke NE, Wiseman JM, Ifa DR, Cooks RG. Desorption electrospray ionization (DESI) mass spectrometry and tandem mass spectrometry (MS/MS) of phospholipids and sphingolipids: ionization, adduct formation, and fragmentation. J Am Soc Mass Spectrom 2008; 19: 531-543

[62] Harris GA, Nyadong L, Fernandez FM. Recent developments in ambient ionization techniques for analytical mass spectrometry. Analyst 2008; 133: 1297-1301

[63] Venter A, Sojka PE, Cooks RG. Droplet dynamics and ionization mechanisms in desorption electrospray ionization mass spectrometry. Anal Chem 2006; 78: 8549-8555

[64] Green FM, Salter TL, Gilmore IS, Stokes P, O’Connor G. The effect of electrospray solvent composition on desorption electrospray ionisation (DESI) efficiency and spatial resolution. Analyst 2010; 135: 731

[65] Badu-Tawiah A, Bland C, Campbell DI, Cooks RG. Non-aqueous spray solvents and solubility effects in desorption electrospray ionization. J Am Soc Mass Spectrom 2010; 21: 572-579

[66] Jackson AU, Talaty N, Cooks RG, Van Berkel G]. Salt tolerance of desorption electrospray ionization (DESI). J Am Soc Mass Spectrom 2007; 18 : 2218-2225

[67] Collins RT, Jones JJ, Harris MT, Basaran OA. Electrohydrodynamic tip streaming and emission of charged drops from liquid cones. Nat Phys 2008; 4: 149-154

[68] Sigmund P, Bitensky IS, Jensen J. Molecule and cluster bombardment: energy loss, trajectories, and collision cascades. Nucl Instruments Methods Phys Res Sect B 1996; 112: 1-11

[69] Kasi SR, Kang H, Sass CS, Rabalais JW. Inelastic processes in low-energy ion-surface collisions. Surf Sci Rep 1989; 10: 1-104

[70] Cooks RG, Jo SC, Green J. Collisions of organic ions at surfaces. Applied Surface Science. 2004; 231: 13-21

[71] Gologan B, Green JR, Alvarez J, Laskin J, Cooks RG. Ion/surface reactions and ion soft-landing. Phys Chem Chem Phys 2005; 7: 1490-1500

[72] Costa AB, Graham Cooks R. Simulated splashes: elucidating the mechanism of desorption electrospray ionization mass spectrometry. Chem Phys Lett 2008; 464: 1-8

[73] Badu-Tawiah AK, Eberlin LS, Ouyang Z, Cooks RG. Chemical aspects of the extractive methods of ambient ionization mass spectrometry. Annu Rev Phys Chem 2013; 64: 481-505

[74] Watrous J, Roach P, Alexandrov T, Heath BS, Yang JY, Kersten RD, van der Voort M, Pogliano K, Gross H, Raaijmakers JM, Moore BS, Laskin J, Bandeira N, Dorrestein PC. Mass spectral molecular networking of living microbial colonies. Proc Natl Acad Sci U S A 2012; 109: E1743-E1752

[75] Lanekoff I, Geydebrekht O, Pinchuk GE, Konopka AE, Laskin J. Spatially resolved analysis of glycolipids and metabolites in living Synechococcus sp. PCC 7002 using nanospray desorption electrospray ionization. Analyst 2013; 138: 1971-1978

[76] Watrous J, Roach P, Heath B, Alexandrov T, Laskin J, Dorrestein PC. Metabolic profiling directly from the Petri dish using nanospray desorption electrospray ionization imaging mass spectrometry. Anal Chem 2013; 85: $10385-10391$ 
[77] Wiseman JM, Ifa DR, Venter A, Cooks RG. Ambient molecular imaging by desorption electrospray ionization mass spectrometry. Nat Protoc 2008; 3: 517-524

[78] Bodzon-Kulakowska A, Drabik A, Ner J, Kotlinska JH, Suder P. Desorption electrospray ionisation (DESI) for beginners - how to adjust settings for tissue imaging. Rapid Commun Mass Spectrom 2014; 28: 1-9

[79] Tillner ], Wu V, Jones EA, Pringle SD, Karancsi T, Dannhorn A, Veselkov K, McKenzie JS, Takáts Z. Faster, more reproducible DESI-MS for biological tissue imaging. J Am Soc Mass Spectrom 2017; 28: 2090-2098

[80] Campbell DI, Ferreira CR, Eberlin LS, Cooks RG. Improved spatial resolution in the imaging of biological tissue using desorption electrospray ionization. Anal Bioanal Chem 2012; 404: 389-398

[81] Thunig J, Hansen SH, Janfelt C. Analysis of secondary plant metabolites by indirect desorption electrospray ionization imaging mass spectrometry. Anal Chem 2011; 83: 3256-3259

[82] Laskin J, Heath BS, Roach PJ, Cazares L, Semmes OJ. Tissue imaging using nanospray desorption electrospray ionization mass spectrometry. Anal Chem 2012; 84: 141-148

[83] Schwartz SA, Reyzer ML, Caprioli RM. Direct tissue analysis using matrixassisted laser desorption/ionization mass spectrometry: practical aspects of sample preparation. J Mass Spectrom 2003; 38: 699-708

[84] Hemalatha RG, Pradeep T. Understanding the molecular signatures in leaves and flowers by desorption electrospray ionization mass spectrometry (DESI MS) imaging. J Agric Food Chem 2013; 61: 7477-7487

[85] Müller T, Oradu S, Ifa DR, Cooks GR, Kräutler B, Müller T, Oradu S, Ifa DR, Cooks RG, Kräutler B. Direct plant tissue analysis and imprint imaging by desorption electrospray ionization mass spectrometry. Anal Chem 2011; 83: $5754-5761$

[86] Ifa DR, Manicke NE, Rusine AL, Cooks RG. Quantitative analysis of small molecules by desorption electrospray ionization mass spectrometry from polytetrafluoroethylene surfaces. Rapid Commun Mass Spectrom 2008; 22: 503-510

[87] Li B, Knudsen C, Hansen NK, Jorgensen K, Kannangara R, Bak S, Takos A, Rook F, Hansen SH, Moller BL, Janfelt C, Bjarnholt N. Visualizing metabolite distribution and enzymatic conversion in plant tissues by desorption electrospray ionization mass spectrometry imaging. Plant J 2013; 74 : 1059-1071

[88] Oetjen J, Veselkov K, Watrous J, McKenzie JS, Becker M, Hauberg-Lotte L, Kobarg JH, Strittmatter N, Mróz AK, Hoffmann F, Trede D, Palmer A, Schiffler S, Steinhorst K, Aichler M, Goldin R, Guntinas-Lichius O, von Eggeling F, Thiele H, Maedler K, Walch A, Maass P, Dorrestein PC, Takáts Z, Alexandrov T. Benchmark datasets for 3D MALDI- and DESI-imaging mass spectrometry. Gigascience 2015; 4: 20

[89] Inglese P, Mckenzie JS, Mroz A, Kinross J, Veselkov K, Holmes E, Takáts Z, Nicholson JK, Glen RC. Deep learning and 3D-DESI imaging reveal the hidden metabolic heterogeneity of cancer. Chem Sci 2017; 8: 3500-3511

[90] Rübel O, Greiner A, Cholia S, Louie K, Bethel EW, Northen TR, Bowen BP. OpenMSI: a high-performance web-based platform for mass spectrometry imaging. Anal Chem 2013; 85: 10354-10361

[91] Song Y, Talaty N, Datsenko K, Wanner BL, Cooks RG. In vivo recognition of Bacillus subtilis by desorption electrospray ionization mass spectrometry (DESI-MS). R Soc Chem 2009; 134: 838-841

[92] Zhang JI, Talaty N, Costa AB, Xia Y, Tao WA, Bell R, Callahan JH, Cooks RG. Rapid direct lipid profiling of bacteria using desorption electrospray ionization mass spectrometry. Int J Mass Spectrom 2011; 301: 37-44

[93] Angolini CFF, Vendramini PH, Araújo FDS, Araújo WL, Augusti R, Eberlin MN, De Oliveira LG. Direct protocol for ambient mass spectrometry imaging on agar culture. Anal Chem 2015; 87: 6925-6930

[94] Figueroa M, Jarmusch AK, Raja HA, El-Elimat T, Kavanaugh JS, Horswill AR, Cooks RG, Cech NB, Oberlies NH. Polyhydroxyanthraquinones as quorum sensing inhibitors from the guttates of Penicillium restrictum and their analysis by desorption electrospray ionization mass spectrometry. J Nat Prod 2014; 77: 1351-1358
[95] Jackson AU, Werner SR, Talaty N, Song Y, Campbell K, Cooks RG, Morgan JA. Targeted metabolomic analysis of Escherichia coli by desorption electrospray ionization and extractive electrospray ionization mass spectrometry. Anal Biochem 2008; 375: 272-281

[96] Tata A, Perez C, Campos ML, Bayfield MA, Eberlin MN, Ifa DR. Imprint desorption electrospray ionization mass spectrometry imaging for monitoring secondary metabolites production during antagonistic interaction of fungi. Anal Chem 2015; 87: 12298-12305

[97] Sica VP, Raja HA, El-Elimat T, Oberlies NH. Mass spectrometry imaging of secondary metabolites directly on fungal cultures. RSC Adv 2014; 4: 63221-63227

[98] Araújo FDS, Vieira RL, Molano EPL, Maximo HJ, Dalio RJD, Vendramin $\mathrm{PH}$, Araújo WL, Eberlin MN. Desorption electrospray ionization mass spectrometry imaging reveals chemical defense of Burkholderia seminalis against cacao pathogens. RSC Adv 2017; 7: 29953-29958

[99] Watrous ], Hendricks N, Meehan M, Dorrestein PC. Capturing bacterial metabolic exchange using thin film desorption electrospray ionizationimaging mass spectrometry. Anal Chem 2010; 82: 1598-1600

[100] Tata A, Perez C], Hamid TS, Bayfield MA, Ifa DR. Analysis of metabolic changes in plant pathosystems by imprint imaging DESI-MS. J Am Soc Mass Spectrom 2015; 26: 641-648

[101] Li B, Bjarnholt N, Hansen H, Janfelt C. Characterization of barley leaf tissue using direct and indirect desorption electrospray ionization imaging mass spectrometry. J Mass Spectrom 2011; 46: 1241-1246

[102] Li B, Hansen SH, Janfelt C. International Journal of Mass Spectrometry direct imaging of plant metabolites in leaves and petals by desorption electrospray ionization mass spectrometry. Int ] Mass Spectrom 2013; 348: $15-22$

[103] Cabral EC, Mirabelli MF, Perez C], Ifa DR. Blotting assisted by heating and solvent extraction for DESI-MS imaging. J Am Soc Mass Spectrom 2013; 24: 956-965

[104] Mohana Kumara P, Srimany A, Ravikanth G, Uma Shaanker R, Pradeep T. Ambient ionization mass spectrometry imaging of rohitukine, a chromone anti-cancer alkaloid, during seed development in Dysoxylum binectariferum Hook.f (Meliaceae). Phytochemistry 2015; 116: 104110

[105] Lane AL, Nyadong L, Galhena AS, Shearer TL, Stout EP, Parry RM, Kwasnik M, Wang MD, Hay ME, Fernandez FM, Kubanek J. Desorption electrospray ionization mass spectrometry reveals surface-mediated antifungal chemical defense of a tropical seaweed. Proc Natl Acad Sci 2009; 106: 7314-7319

[106] Andras TD, Alexander TS, Gahlena A, Parry RM, Fernandez FM, Kubanek J, Wang MD, Hay ME. Seaweed allelopathy against coral: surface distribution of a seaweed secondary metabolite by imaging mass spectrometry. J Chem Ecol 2012; 38: 1203-1214

[107] Eberlin LS, Norton I, Dill AL, Golby AJ, Ligon KL, Santagata S, Cooks RG, Agar NYR. Classifying human brain tumors by lipid imaging with mass spectrometry. Mol Cell Pathobiol 2012; 72: 645-655

[108] Banerjee S, Zare RN, Tibshirani RJ, Kunder CA, Nolley R, Fan R, Brooks JD, Sonn GA. Diagnosis of prostate cancer by desorption electrospray ionization mass spectrometric imaging of small metabolites and lipids. PNAS 2017; 114: 3334-3339

[109] Miyamoto S, Hsu CC, Hamm G, Darshi M, Diamond-Stanic M, Declèves AE, Slater L, Pennathur S, Stauber J, Dorrestein PC, Sharma K. Mass spectrometry imaging reveals elevated glomerular ATP/AMP in diabetes/obesity and identifies sphingomyelin as a possible mediator. EBioMedicine 2016; 7: 121-134

[110] Naraoka H, Hashiguchi M. In-situ organic compound analysis of the meteorite surface by desorption electrospray ionization coupled with an orbitrap mass spectrometer. In: 79th Annual Meeting of the Meteoritical Society August 7-12, 2016. Meteorit Planet Sci 2016; 51: 6169

[111] Woolman M, Tata A, Bluemke E, Dara D, Ginsberg H], Zarrine-Afsar A. An assessment of the utility of tissue smears in rapid cancer profiling 
with desorption electrospray ionization mass spectrometry (DESI-MS). J Am Soc Mass Spectrom 2017; 28: 145-153

[112] Eberlin LS, Norton I, Orringer D, Dunn IF, Liu X, Ide JL, Jarmusch AK, Ligon KL, Jolesz FA, Golby AJ, Santagata S, Agar NYR. Ambient mass spectrometry for the intraoperative molecular diagnosis of human brain tumors. PNAS 2013; 110: 1611-1616

[113] Woolman M, Tata A, Dara D, Meens ], D'Arcangelo E, Perez C, Prova S, Bluemke E, Ginsberg H, Ifa D, McGuigan A, Ailles L, Zarrine-Afsar A. Rapid determination of tumour stroma ratio in squamous cell carcinomas with desorption electrospray ionization mass spectrometry (DESI-MS): a proof-of-concept demonstration. Analyst 2017; 142: 3250-3260

[114] Lisboa A, Alves-júnior M, Vilczaki N, Nogueira M, Almeida A, Sussulini A. Lipid mapping by desorption electrospray ionization mass spectrometry in a murine breast DMBA carcinogenesis model. Int J Mass Spectrom 2016; 418: 86-91

[115] Sans M, Gharpure K, Tibshirani R, Zhang J, Liang L, Liu J, Young JH, Dood RL, Sood AK, Eberlin LS. Metabolic markers and statistical prediction of serous ovarian cancer aggressiveness by ambient ionization mass spectrometry imaging. Cancer Res 2017; 77: 2903-2913
[116] Cooks RG, Manicke NE, Dill AL, Ifa DR, Eberlin LS, Costa AB, Wang H, Guangming $\mathrm{H}$, Ouyang Z. New ionization methods and miniature mass spectrometers for biomedicine: DESI imaging for cancer diagnostics and paper spray ionization for therapeutic drug monitoring. $\mathrm{R}$ Soc Chem 2011; 149: 247-267

[117] Kauppila TJ, Talaty N, Kuuranne T, Kotiaho T, Cooks RG. Rapid analysis of metabolites and drugs of abuse from urine samples by desorption electrospray ionization-mass spectrometry. Analyst 2007; 132: 868875

[118] Zhang J, Feider CL, Nagi C, Yu W, Carter SA, Suliburk J, Cao HST, Eberlin LS. Detection of metastatic breast and thyroid cancer in lymph. J Am Soc Mass Spectrom 2017; 28: 1166-1174

[119] Ferreira CR, Pirro V, Eberlin LS, Hallett JE, Cooks RG. Developmenta phases of individual mouse preimplantation embryos characterized by lipid signatures using desorption electrospray ionization mass spectrometry. Anal Bioanal Chem 2012; 404: 2915-2926

[120] González-Serrano AF, Pirro V, Ferreira CR, Oliveri P, Eberlin LS, Heinzmann J, Lucas-Hahn A, Niemann H, Cooks RG. Desorption electrospray ionization mass spectrometry reveals lipid metabolism of individual oocytes and embryos. PLoS One 2013; 8: 1-11 